\title{
Differences in the severity of the phenotype of children and adolescents with Familial Mediterranean Fever residing in Turkey and Germany
}

\author{
N Aktay Ayaz*1,2,3, S Özen ${ }^{1}$, E Lainka1, E Taskiran¹ , A Duzova ${ }^{1}$, N Besbas ${ }^{1}$, \\ A Bakkaloglu ${ }^{1}$ and T Kallinich ${ }^{1}$
}

\author{
Address: ${ }^{1}$ Hacettepe University Medical Faculty, Ankara, Turkey, ${ }^{2}$ University of Duisburg, Essen, Germany and ${ }^{3}$ Charite University Hospital, Berlin, \\ Germany \\ * Corresponding author
}

\author{
from I5th Paediatric Rheumatology European Society (PreS) Congress \\ London, UK. 14-17 September 2008 \\ Published: 15 September 2008 \\ Pediatric Rheumatology 2008, 6(Suppl I):PI79 doi:I0.II86/I546-0096-6-SI-PI79
}

This abstract is available from: http://www.ped-rheum.com/content/6/SI/PI79

(c) 2008 Ayaz et al; licensee BioMed Central Ltd.

Familial Mediterranean Fever (FMF) is worldwide the most common autoinflammatory disease. It has been long known that environmental factors affect the phenotype.

To substantiate this hypothesis we compared the diseaseseverity in Turkish FMF patients living in Turkey and Germany, based on a modified score for children. A total of 53 Turkish children living in Turkey were compared to 45 Turkish children born and raised in Germany. Mean age among the group from Turkey and Germany was 42.2 (range 2-120 months) and 44.29 (range 3-178 months) months, respectively. M694V was the leading mutation in both groups. The score developed by Livneh et al was modified by the integration of the recommended agerelated doses, previously published by us. Additionally, disease severity was determined by the use of the scoring system developed by Pras et al. There was no correlation between the disease severity defined by the different scoring systems and the acute phase reactants.

According to the modified Livneh score, $78.2 \%$ of patients from the group living in Turkey had a severe course compared to $34.1 \%$ from the group living in Germany. Pras scores were also higher in the patients born and grown up in Turkey $(34.5 \%)$ compared to patients living in Germany (15.4\%). The difference between the two groups for both scoring systems were statistically significant $(\mathrm{p}<$ 0.05 for both).

We suggest that environmental factors may affect the severity of FMF even if they were coming from the same ancestors. 